\title{
Endoscopy-assisted technique for removal of a transduodenal T-tube
}

In contemporary surgical practice, placement of a T-tube, which is a common procedure following exploration of the common bile duct, has been extended to the management of large duodenal perforations/injuries as well as esophageal perforations when primary repair is considered inappropriate [1-3]. In addition to providing controlled drainage (enterocutaneous fistula), the rationale behind this use of the T-tube is to reduce suture line tension to preclude tissue edema secondary to the injury, resuscitation, and operation [4].

There is a lack of literature on the ideal method and timing of removal of the $\mathrm{T}$ tube following its use. Usually the tract is deemed to have matured after 6 weeks, and, if the patient's condition allows, the T-tube is removed. The traditional procedure for removal involves application of traction onto the external part of the tube. This method is fraught with complications including disruption of the tract and subsequent leaks [5].

We describe a simple method of T-tube removal from the duodenum using an endoscope, without the inherent risk of damage to the matured enterocutaneous tract. Upper gastrointestinal endoscopy is required to position the horizontal limb of the Ttube inside the duodenum ( Fig. 1a), where the tube is then held with standard endoscopic graspers/forceps.

Next, a gentle tug is applied to the grasper to ensure/confirm ease of sliding of the vertical limb of the T-tube ( Fig. 1b) and following this the vertical limb is divided flush with the skin ( $\bullet$ Fig. 2).

The grasped T-tube is then slowly removed as the gastroscope is withdrawn. - Fig. 3 shows the T-tube exiting the esophagus.

The method is simple, requiring only basic endoscopic skills, and causes minimal patient discomfort. To date, we have had no failures or complications and will advocate its use routinely. Furthermore, the technique could also potentially be used in the removal of a T-tube from the esophagus.

Endoscopy_UCTN_Code_TTT_1AO_2AI

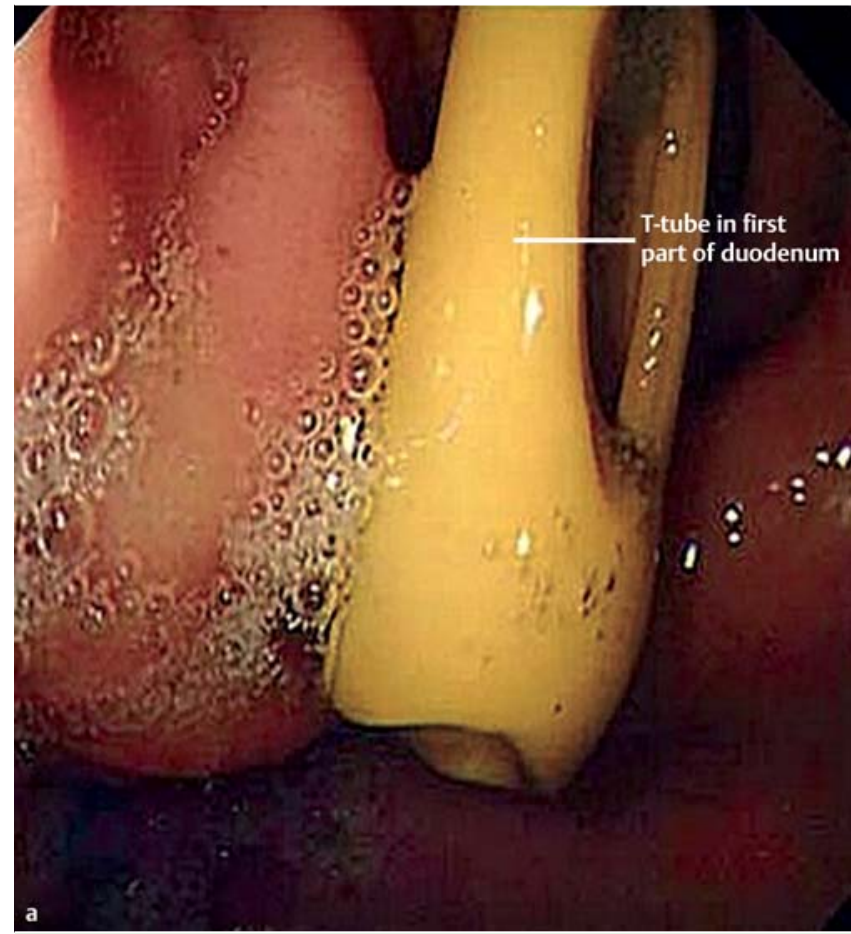

Fig. 1 Endoscopic views showing: a the horizontal limb of the T-tube inside the duodenum; and $\mathbf{b}$ the grasped T-tube inside the duodenum during the gentle tug procedure.

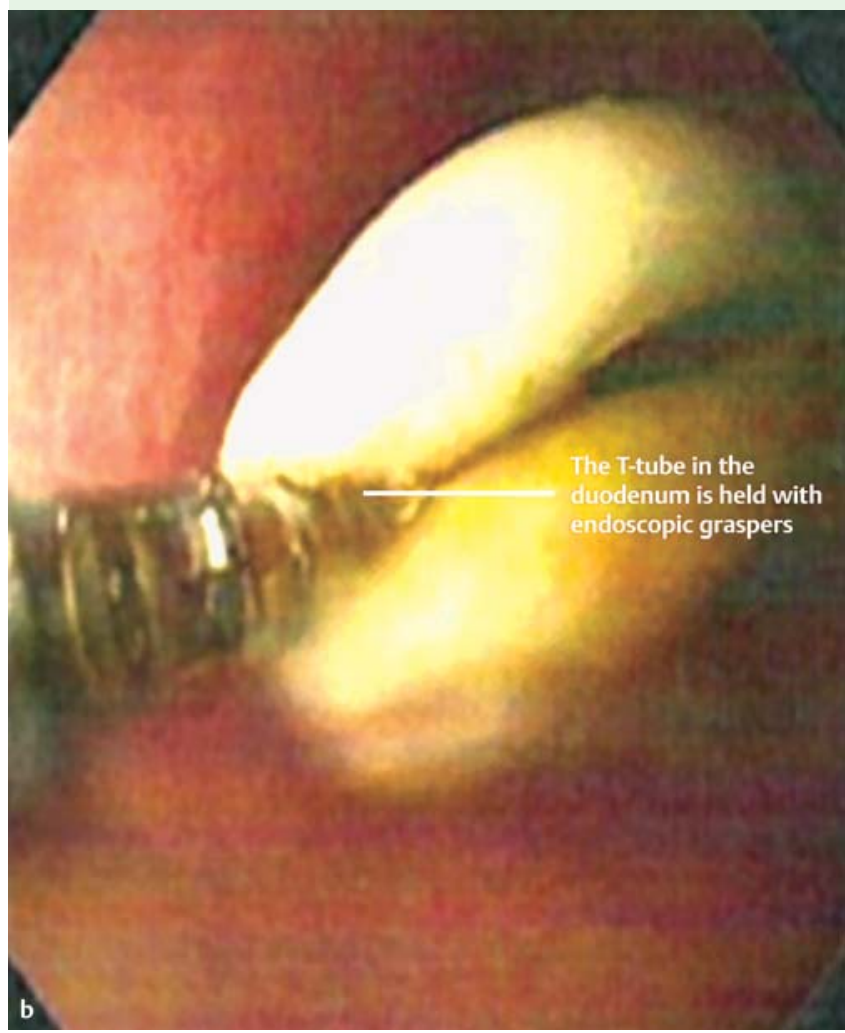




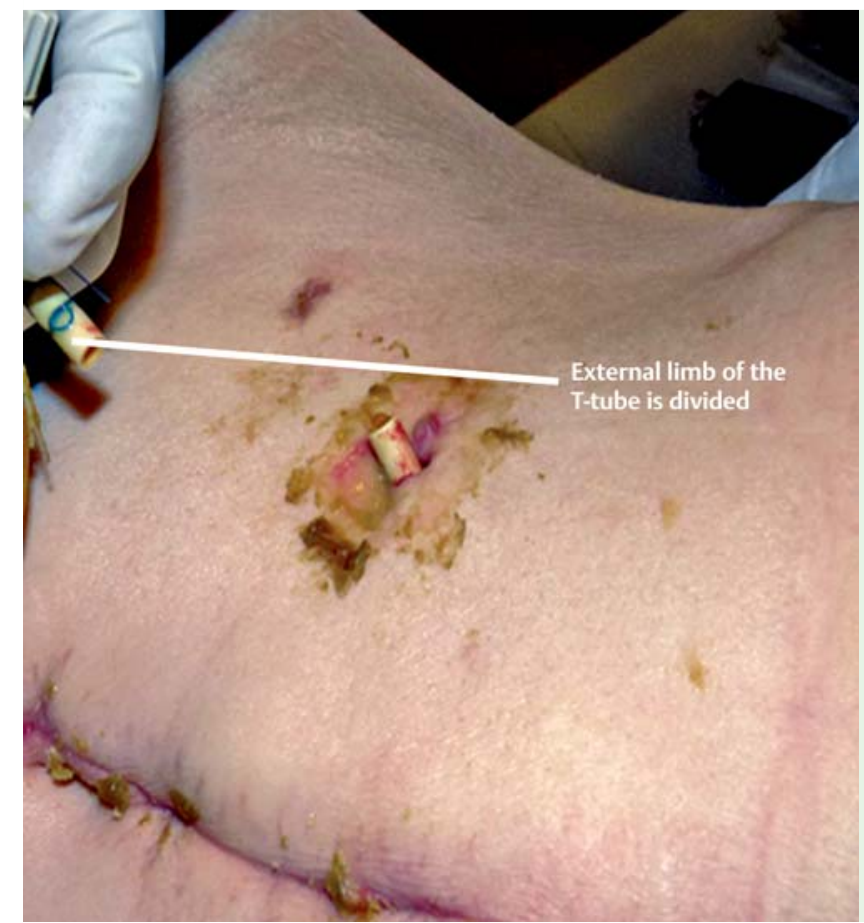

Fig. 2 The vertical limb of the T-tube has been divided flush with the skin.

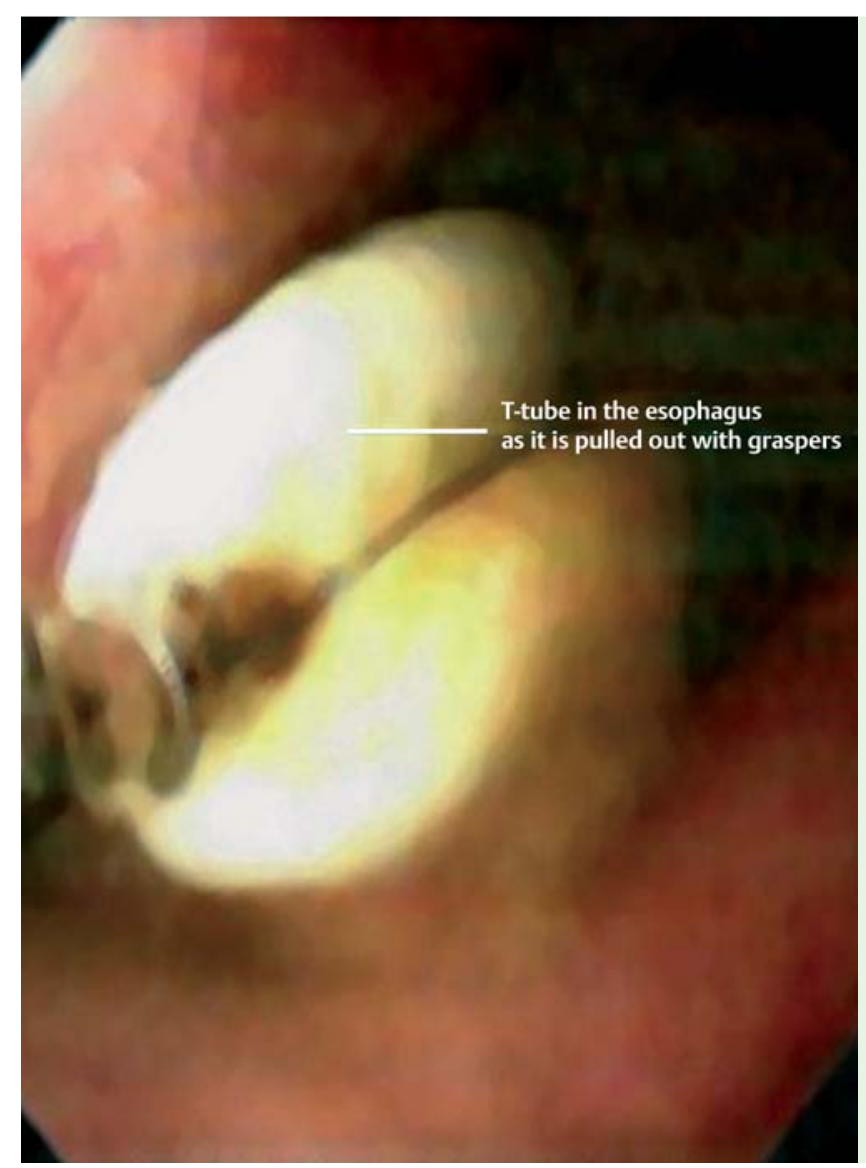

Fig. 3 Endoscopic view of the grasped T-tube being pulled out of the esophagus.

\section{Chattopadhyay, D. Garkuwa,}

\section{K. S. Wynne, B. V. Joypaul}

Department of General Surgery, South Tyneside District Hospital,

South Shields, UK

\section{References}

1 Isik B, Yilmaz S, Kirimlioglu Vet al. A life-saving but inadequately discussed procedure: tube duodenostomy. Known and unknown aspects. World J Surg 2007; 31: 1616 1624; discussion 1625-1626

2 Lal P, Vindal A, Hadke NS. Controlled tube duodenostomy in the management of giant duodenal ulcer perfortion - a new technique for a surgically challenging condition. Am J Surg 2009; 198: 319-323

3 Griffin SM, Lamb PJ, Shenfine J et al. Spontaneous rupture of the oesophagus. Br J Surg 2008; 95: 1115-1120

4 Rathore MA, Andrabi SL, Najfi SM et al. Injuries to the duodenum - prognosis correlates with body Injury Severity Score: a prospective study. Int J Surg 2007; 5: 388 - 393

5 Kacker LK, Mittal BR, Sikora SS et al. Bile leak after T-tube removal - a scintigraphic study. Hepatogastroenterology 1995; 42: 975978

Bibliography

DOI $10.1055 / \mathrm{s}-0030-1255769$

Endoscopy 2011; 43: E7-E8

(c) Georg Thieme Verlag KG Stuttgart . New York . ISSN 0013-726X

\section{Corresponding author}

\section{B. V. Joypaul}

Department of Surgery

South Tyneside District Hospital

Harton Lane

South Shields NE34 OPL

UK

Vickram.Joypaul@sthct.nhs.uk 